\title{
Continued dialogue in building a culture of self-sufficiency
}

\author{
Shannon McLain ${ }^{\mathrm{a}, *}$, Malana Walus ${ }^{\mathrm{b}}$ and Steven Chapman ${ }^{\mathrm{c}}$ \\ ${ }^{a}$ Embassy Management/SL Start \& Associates, LLC, Grand Canyon University, Spokane, WA, USA \\ ${ }^{\mathrm{b}}$ Individual Advocacy Group, Grand Canyon University, Bloomingdale, IL, USA \\ ${ }^{\mathrm{c}}$ Lower Columbia College Career Center, Longview, WA, USA
}

Revised/Accepted November 2015

\begin{abstract}
.
BACKGROUND: A group of individuals continued exploration of the concepts of community engagement, inclusion, supported employment and poverty.

OBJECTIVE: The original conversation took place at the APSE 2014 National Conference. This current discussion was an open interactive dialogue in a network café style.

CONCLUSION: Society continues to transform. Through an inclusive discussion of professionals working with the ID population, a great deal of information has been yielded about where this culture is with regards to self-sufficiency.

Keywords: Community engagement, culture, gainful employment, inclusion, individuals with intellectual disability (ID), normalization, poverty, Social Role Valorization (SVR), supported employment, Workforce Innovation and Opportunity Act
\end{abstract}

\section{Introduction}

The American Dream is "a land in which life should be better and richer and fuller for everyone, with opportunity for each according to ability or achievement" (Adams, 1931). The American Way to stability and reaching dreams is by achieving gainful employment through employability. Achieving employability is a goal for everyone in America who desires a family, a roof over their head, food in their stomach, and community providing support and encouragement. To make incremental transformational changes such as building a community evolving towards Mank's (2008) "All Means All" movement, continued dialogue must occur exploring

\footnotetext{
*Address for correspondence: Shannon McLain, Embassy Management/SL Start \& Associates, LLC, Grand Canyon University, 5709 W Sunset Hwy Suite 100, Spokane, WA 99224, USA. Tel.: +1 509209 2693; Fax: +1 509326 9207; E-mail: smclain 02@my.gcu.edu; http://www.slstart.com/employment-services/
}

diversity, inclusion, non-segregation, and employment. Persons identified as intellectually disabled (ID) can be a self-advocate and advocate within the community.

During the 2015 APSE conference in Philadelphia, Shannon McLain, Malana Walus, and Steven Chapman provided a break-out session in the form of a World Café to gather information on how community affects individuals with ID to be self-sufficient. This continued discussion on the role society plays in improving advocacy, community engagement, and equitability in the everyday lives of people with ID. The takeaways from the 2015 APSE identified the importance of discovery and a discussion of 'what do you want to be when you grow up' at an early stage and continuous through youth, and education of benefits such as PASS (Plan to Achieving Self-Support) planning. Individual success stories are important to expose as this promotes one's ability to the community, at-large (2015). 


\section{Literature review}

\subsection{Normalization, social role valorization and community life engagement}

A journey through history shows a cultural quantum leap in the 1960's of normalizing communities towards acceptance of diversity (Wolfensberger \& Nirje, 1972). Normalization is a concept providing acceptance of person regardless of ethnicity, gender, religion, or disability (Corrigan, 2001; Place-thenTrain). Approximately 40 years later, Wolfensberger $(1999,2011)$ recalibrated the normalization concept with Social Role Valorization (SRV). SRV proposes that normalization is not enough to explain the difficulty in mainstreaming inclusive behaviors within society. SRV enables, establishes, enhances, maintains, and defends valued social roles within the ID population and it does this by personal competencies (Wolfensberger, 1999, 2011; Aubry et al., 2013). It is imperative that every human being receives acceptance within their community and that individuals are valued for their contributions made within the community. Every ID individual has transferable skills that can correspond with community education or vocation. It is our belief that not only every individual contribute, but they are also a valued part of the community.

Early in the year 2015, the Institute for Community Inclusion (ICI) began promoting another evolution of the normalization concept. This modernization, known as Community Life Engagement includes all individuals with the hope for an engaging, prosperous, and independent lifestyle. The basic premise is that all individuals, including individuals with ID, have the opportunity to become employed, live independently in an inclusive community, and rise out of poverty (Sullivan, Sutewski, \& Timmons, 2015).

In the United States, over 34\% of individuals with ID who are employed are also in poverty. Conversely, the other $66 \%$ are not reported as employed or unemployed as they are not reported (Sullivan \& Nord, 2015). Community plays a vital role in the culture of poverty. As culture continues to shift and evolve this discussion must continue until full community life engagement for all individuals, with no preconceived ideations of barriers, exists. Evolution requires actions within a community, communication, and coming together to achieve a resolution of the issues of employment and poverty among individuals with ID.

\subsection{Workforce innovation and opportunity act, also known as 'opportunity act'}

People with disabilities represent a vital and integral part of our society. We, as a community, must commit to ensuring that individuals with disabilities have equitable opportunities to compete for and enjoy high-quality employment in the 21st-century global economy. Some individuals with disabilities face particular barriers to high-quality employment. Giving workers with disabilities the supports and the opportunity to acquire the skills that they need to pursue in-demand jobs and careers is critical to growing our economy, ensuring that everyone who works hard is rewarded, and building a strong middle class. To help achieve this priority for individuals with disabilities, the Rehabilitation Act of 1973 was created. The Rehab Act was amended in 1998 to the Workforce Investment Act (WIA). Currently, the WIA is changing to the Workforce Innovation Opportunity Act (Opportunity Act) which seeks to empower individuals with disabilities to maximize employment, economic self-sufficiency, independence, and inclusion and community engagement (U.S. Department of Education, 2015).

State Vocational Rehabilitation (VR) programs assist in operating statewide comprehensive, coordinated, effective, efficient, and accountable inclusivity measures. State programs act as an integral part of a statewide workforce development system; and to assess, plan, and provide VR services to individuals with ID. VR programs prepare for and engage individuals with ID in competitive integrated employment positions that are consistent with an individual's unique strengths, priorities, concerns, abilities, capabilities, interests, and informed choices.

The Opportunity Act places heightened emphasis on the achievement of competitive integrated employment. The foundation of the VR program is the principle that individuals with disabilities, including those with the most significant disabilities, are capable of achieving high quality, competitive integrated employment when provided the necessary skills and supports. VR programs provide many individuals with the necessary skills and supports increasing their employability in the competitive labor market. The workforce system must provide the opportunity for such individuals to participate in job-driven training and pursue high-quality employment outcomes. The inclusion of limitations on the payment of subminimum wages to individuals with disabilities reinforce the congressional intent that individuals 
with disabilities, with appropriate supports and services, can achieve the same kinds of competitive integrated employment as non-disabled individuals.

The Opportunity Act amended the definition of "employment outcome" to include only those outcomes in competitive integrated employment or supported employment, eliminates uncompensated and the undercompensation of employment from the scope of employment outcomes. Congress reinforces its intention that individuals with ID should not be allowed to languish in subminimum wage jobs under the supported employment program. Outcomes intended to maximize the potential for individuals with disabilities to prepare for, obtain, retain, and advance in the same high-quality jobs, and high demand careers as individuals without disabilities.

\section{Network café}

This presentation is a continued exploration of three questions identified at the APSE (The Association of People Supporting Employment First) 2014 Conference. This exploration encompassed the conversation of social role valorization (SVR), normalization, poverty, and the inclusion of individuals who are in a supported employment programs throughout the United States and are individuals with ID. The questions:

1. Are individuals receiving supported employment services self-sufficient (able to live comfortable with little to no government subsidy)?

2. Are persons receiving supported employment services in poverty?

3. Does government funding promote selfsufficiency?

These three questions were inally presented during a group conversation at the 2014 APSE Conference in Philadelphia, PA with opportunity for dialogue. These three questions were brought forward again in 2015. Table 1 provides the actual responses from the dialogue.

\subsection{Most effective}

Overall, the facilitators acknowledge an increase in the receptivity to the continued discussion of community inclusion, poverty, and employment among individuals identified with ID. There was a great deal of feedback throughout the breakout session that yielded information beneficial to an inclusive culture shift. Each question has been broken down by findings.

1. Are individuals receiving supported employment services self-sufficient (able to live comfortably with little to no government subsidy)?

While many individuals are receiving supported employment services through a state Medicaid program or VR through the Department of Social and Health Services (DSHS), the question of selfsufficiency and an ability to live comfortably and independently with little to no government subsidy seemed to weigh heavily on participants. There is not a one-size-fits-all formula to assisting the ID population as every individual's needs vary widely. While there are some individuals with ID not needing Medicaid supports, there are others who do. This has primarily been identified as a result of early intervention and self-employment. Individuals within this category also receive encouragement from the community for utilizing natural supports first (i.e., immediate family and friends). There are also individuals with ID who are presently working 40 hours per week and unable to receive supportive services and medical benefits due to their wage and hours worked. There are opportunities to purchase benefits through the DSHS Healthcare for Workers with Disability (HWD). At times, the cost of such benefits is extreme in consideration of weighing cost with income.

Outside of DSHS, many of the population with ID have limited personal resources to fund long-term job coaching and vocational development. Participants briefly discussed the strains of maintaining staffing needs to provide proper supportive services as well as continued training for direct support staff. There also exists an income restriction when it comes to healthcare for some ID individuals who ultimately earn up to $250 \%$ of Federal poverty level. Participants reported that there are discussions for possible solutions. It was also discussed that it is only on very rare occasions that any member of the community will see individuals with ID holding state/county government jobs. The reasoning for this is unknown and can be something to discuss at future conferences.

\section{Are persons receiving supported employment services in poverty?}

Unfortunately, one of the most effective points of this discussion was that there remains only a minimal amount individuals with ID out of poverty. Few 
Table 1

Community culture in the role of self-sufficiency APSE 2015

\begin{tabular}{|c|c|c|c|}
\hline Question & Most Effective & Least Effective & Future Hope \\
\hline $\begin{array}{l}\text { 1. Are individuals receiving } \\
\text { supported employment } \\
\text { services self-sufficient } \\
\text { (able to live comfortable } \\
\text { with little to no government } \\
\text { subsidy)? }\end{array}$ & $\begin{array}{l}\text { - When they don't need } \\
\text { supports via Medicaid } \\
\text { - Early intervention; } \\
\text { self-employment } \\
\text { - Encouraging natural supports } \\
\text { - Working } 40 \text { hours per week } \\
\text { - Medicaid buy-in } \\
\text { - Limited job coaching } \\
\text { - Healthcare for workers with } \\
\text { income restriction can earn } \\
\text { up to } 250 \% \text { of Federal } \\
\text { poverty level } \\
\text { - Hub in WA/MAD in Penn } \\
\text { and sliding scale after that } \\
\text { - Rare occasion } \\
\text { 1\%-state/county government } \\
\text { jobs }\end{array}$ & $\begin{array}{l}\text { - People losing service due to } \\
\text { salary does not qualify them } \\
\text { - Continuing sheltered } \\
\text { workshops } \\
\text { - Familial fear/hesitation } \\
\text { because benefits and checks } \\
\text { - People do not take } 40 \text { hour } \\
\text { per week jobs because the } \\
\text { loss of benefits could take so } \\
\text { long to get back on to be } \\
\text { eligible for benefits-have to } \\
\text { prove what you cannot do. } \\
\text { - Using SSI/SSDI benefit } \\
\text { doesn't promote change. } \\
\text { - 99\%, not self-sufficient afraid } \\
\text { of losing benefits, limit hours } \\
\text { artificially }\end{array}$ & $\begin{array}{l}\text { - All states have an income } \\
\text { level that allows them to be } \\
\text { out of poverty and keep } \\
\text { supports/services and are not } \\
\text { tied to earnings. } \\
\text { - Building practical examples } \\
\text { changing perceptions } \\
\text { aligning funding with } \\
\text { outcomes matching systems } \\
\text { - Raise the bar/expectations } \\
\text { - Understanding work } \\
\text { incentives, helping to move } \\
\text { beyond the fear of losing } \\
\text { benefits, educating families } \\
\text { of individuals at an early age. }\end{array}$ \\
\hline $\begin{array}{l}\text { 2. Are persons receiving } \\
\text { supported employment } \\
\text { services in poverty? }\end{array}$ & $\begin{array}{l}\text { - Only minimal amount of } \\
\text { people are out of poverty } \\
\text { - Education/discussion } \\
\text { strategies about benefits } \\
\text { - Generational poverty } \\
\text { - Few people in supported } \\
\text { employment not in } \\
\text { poverty-make 40k (no } \\
\text { longer receiving services) } \\
\text { - Private pay clients } \\
\text { - Trust. Find clients? Who have } \\
\text { jobs? }\end{array}$ & $\begin{array}{l}\text { - Promotes poverty } \\
\text { - Sheltered workshops/minimal } \\
\text { hours } \\
\text { - Ignoring that disparity exists } \\
\text { - People working full-time but } \\
\text { making pie cc rate (way } \\
\text { below poverty) } \\
\text { - Working poor moving toward } \\
\text { self-sufficiency }\end{array}$ & $\begin{array}{l}\text { - National initiatives to stop } \\
\text { sub = minimal wage } \\
\text { - Increase in employer } \\
\text { knowledge } \\
\text { - Increase in educators models } \\
\text { of support to raise } \\
\text { employment outcomes } \\
\text { - APSE initiative to promote } \\
\text { employment first. } \\
\text { - Formulating ways for } \\
\text { work/benefits to match up } \\
\text { - Confronting brutal facts put } \\
\text { self-sufficiency on the table } \\
\text { - Go from } 9 \text { hours to more so } \\
\text { they all are successful }\end{array}$ \\
\hline $\begin{array}{l}\text { 3. Does government funding } \\
\text { promote self-sufficiency? }\end{array}$ & $\begin{array}{l}\text { - SSA work incentives \& } \\
\text { ABLE Act } \\
\text { - Utilization of work incentives } \\
\text { - Opportunity Act allowing } \\
\text { people to return to vocational } \\
\text { rehabilitation for career } \\
\text { advancement }\end{array}$ & $\begin{array}{l}\text { - The formula keeps people } \\
\text { from wanting more or higher } \\
\text { incomes } \\
\text { - The continued gap between } \\
\text { reliance on getting } \\
\text { funding/losing funding too } \\
\text { soon. } \\
\text { - "Silo" based on } \\
\text { funding/where you can go } \\
\text { - Limitations on who can } \\
\text { receive } \\
\text { - Culture of entitlements } \\
\text { - Reward for not using } \\
\text { government benefit (e.g. } \\
\text { unemployment) }\end{array}$ & $\begin{array}{l}\text { - People will have expectations } \\
\text { that include high salaries, } \\
\text { home ownership, college, } \\
\text { extras. } \\
\text { - Inter-agency collaboration } \\
\text { helps } \\
\text { - Pull together all } \\
\text { stakeholders-cross systems } \\
\text { align funding. } \\
\text { - System change to incentives } \\
\text { employment not } \\
\text { unemployment } \\
\text { - System of past (institutions) }\end{array}$ \\
\hline
\end{tabular}

people in supported employment are not in poverty any longer. There also exist many individuals who are private pay and trust fund individuals. Numbers of individuals in such a circumstance vary from stateto-state, and it is unknown whether or not these individuals have employment. Better-prepared parents have yielded in proactive planning for the futures of their children identified as an individual with ID.

Another most effective topic brought up in this discussion is that the changes in education, stemming from No Child Left Behind (NCLB) has created a shift in the skills and abilities of individuals with ID. Better educated individuals are more able to have a discussion with caregivers about their benefits and have a desire to be self-sufficient.

3. Does government funding promote selfsufficiency?

The most effective factor identified to promote selfsufficiency was government funding. This includes 
the Social Security Association's (SSA) work incentives \& the 2014 Achieving a better Life Experience (ABLE) Act. The utilization of work incentives and the federally mandated updates of the Opportunity Act allow more attention to be focused toward people returning to vocational rehabilitation for more than job attainment, but also career advancement.

\subsection{Most ineffective}

1. Are individuals receiving supported employment services self-sufficient (able to live comfortably with little to no government subsidy)?

There remains a great deal that is ineffective with individuals receiving supported employment services. Many individuals with ID have fears of losing or do lose services due to a salary that does not qualify them. Sheltered workshops still stymie a great deal of persons with ID. Ensuring individuals with ID live comfortably may also affect people within a person's immediate community. Familial fears and hesitation regarding the risk of the natural rise and fall of a career can then affect an individual because as long as benefits and checks come in there is a feeling of security that is maintained. Alongside these fears exists perception that it is important not to take 40-hour per week jobs because of the potential loss of benefits and the fear of how long reinstatement may take if there is a job loss. Maintaining eligibility for benefits means a person has to prove what they cannot do. This is quasi-productive when a person is trying very hard to prove what they can do.

The largest ineffective issue discussed revolved around the utilizing of SSA benefits does not promote change for the general population. Many participants felt that this ineffectiveness is just cause for a restructuring of how SSA works because $99 \%$ of ID individuals are not self-sufficient and afraid of losing benefits. For many receiving SSA benefits, there may exist an opportunity to work more, but there is a limitation of hours artificially to ensure benefits continue.

2. Are persons receiving supported employment services in poverty?

The initial response to this question from the group of participants was that individuals with ID receiving supported employment services are in poverty. In fact, the way that the current system is set up, poverty is promoted. It was inferred that there is a great deal of ignorance in the field and among professionals, when it comes to the existence of this disparity. There need to be more discussions on how the working poor move toward self-sufficiency, because many people who are working full-time are still earning wages that are far below the poverty level.

It was the consensus that further discussion is also needed on sheltered workshops and vocational training. Specifically, there are some programs where no movement is made with regards to transitioning individuals to meet their vocational training objectives and/or a job in the community at a competitive rate. What does this ideally look like for an individual? Should programs have a timeframe on when it is a proper time to transition an ID person out of their program?

3. Does government funding promote selfsufficiency?

The current programs that government funding has created for individuals with disability to receive benefits have created a formula for individuals not to want to achieve more or higher incomes. The group's perception was that government funding does not promote self-sufficiency. Instead, we find a continued gap between reliance on getting funding and losing funding. There are limitations on who can receive government funding.

There was a deep discussion on how the present culture of the American people is one of entitlement. Everything that an individual does tends to be centered on self, and to what entitlement, the individual is eligible. There needs to be a culture shift through systematic changes in how government funding works to provide individuals with rewards for not using government benefits (e.g. unemployment). The Opportunity Act appears to be a step in the right direction.

\subsection{Future hope}

1. Are individuals receiving supported employment services self-sufficient (able to live comfortable with little to no government subsidy)?

Based upon this discussion, persons with ID are not self-sufficient although conversational progress continues to be made. It is believed that in the future all states need to have an income level that can enable 
individuals with ID to be out of poverty while still maintaining supports/services that are not tied to earnings. We must build effective examples, change perceptions, and align funding with current outcomes matching systems that are presently in place. To do this, we must raise the bar on the expectations society has for every individual.

Furthermore, a deeper understanding of work incentives, helping ID individual to move beyond the fear of losing benefits, and educating families of individuals at an early age, will cause additional cultural shifts to occur leading to self-sufficiency within the community.

\section{Are persons receiving supported employment services in poverty?}

Unfortunately, many individuals receiving supportive employment remain in poverty but in the future, there are things we can do to manifest changes. National initiatives to stop sub-minimum wage rates are only a step in this process. Additionally, we must increase employer knowledge and build partnerships on how benefits work for the ID population. There must also be an increase in educators' models of support to raise employment outcomes in students identified as ID.

A great deal of hope is placed upon the APSE initiative to promote Employment First by continuing to formulate ways for work/benefits to match up for workers with ID. Discussions such as these, which confront brutal facts, put self-sufficiency on the table and remain as a hope for the individual with ID's potential for achieving self-sufficiency in the future. As long as people exist to advocate for themselves and the needs of those with ID, incremental changes will continue to shift.

\section{Does government funding promote self- sufficiency?}

While current government funding programs do not promote self-sufficiency, future hope exists that, as inclusive behaviors continue, people with ID will have expectations that include high salaries, home ownership, college, and etcetera. Self-sufficiency can be achieved through inter-agency collaboration, pulling together all stakeholders and cross-systems, and aligning funding. Participants would like to see government systems change to incentives for employment, not unemployment.

\section{Findings and reflections}

\subsection{Discussion}

There is a continued belief that NCLB is yielding positive results by creating a generation of inclusion/non-segregation and self-sufficiency. We continue to remain at least one generation into the inclusive classroom and NCLB with children becoming adults that have been left behind (McLain \& Walus, 2015). Manifesting change takes time and requires the collaboration of all stakeholders at the local, state, and federal level. Recently the importance of adult education and achieving the "American Dream" was discussed in a speech by Vice President, Joe Biden. The "American Dream" is achievable for every American, including those with ID. Advocacy work and discussions that enable professionals in the field to evaluate how self-sufficiency has progressed annually has yielded positive results in the culture of self-sufficiency.

\subsection{Conclusion}

Transformational societal changes continue to manifest. Through an inclusive discussion of professionals working with the ID population, a great deal of information has been yielded about where this culture is with regards to self-sufficiency. Continued discussion is necessary regarding this population's integral and critical value within the community.

The current Opportunity Act (U.S. Department of Education 2015) has yielded a great deal of progress in just one year. Every state has adopted Opportunity Act and has begun to make changes to policies assisting individuals with ID to access the tools needed to achieve employment. Change continues to take time to manifest and the dream of Mank's (2008) "All Means All" philosophy has not yet been actualized. For this purpose, this research continues to be relevant as does the need for further discussions, as inclusive practices and policy changes continue to manifest nationwide.

\section{References}

Adams, J. T. (1931). The Epic of America.

Aubry, T., Flynn, R. J., Virley, B., \& Neri, J. (2013) Social role valorization in community mental health housing: Does it contribute to the community integration and life satisfaction of people with psychiatric disabilities? Journal of community psychology, 41(2), 218-235. 
Bergman, A. (2013). APSE Conference Indianapolis, Indiana. https://mail.google.com/mail/u/0/?shva=1\#search/apse/1400c 9b8d6c3e8b9

Bohm, D., Factor, D., \& Garrett, P. (1991). Dialogue - A proposal. Retrieved from http://www.infed.org/archives/e-texts/bohm dialogue.htm

Bradford, A. (1999). Guidelines for dialogue. http://www.cct. umb.edu/guidelinesdia.htm (viewed 2 Jan 2012)

Chaffee, J. (2012). Critical Thinking, Thoughtful Writing. (5th Ed.). Boston, MA: Cengage Learning Wadsworth. ISBN-13:97 8-0-495-89978-5; ISBN-10:0-495-89978-X

Corrigan, P. W. (2001). Place-then-Train. https://www.questia. com/library/journal/1G1-127623544/place-first-then-trainan-alternative-to-the-medical

DiLeo, D. (2007). Raymond's Room. St. Augustine, Florida: Training Resource Network, Inc. doi: 10.1352/1934-9556-49.4.ii

Isaacs, W. (1999). Dialogue and the Art of Thinking Together. New York: Currency.

Kellerman, B. (2008). Claiming the bad side: Recognizing both the good and the bad sides of leadership. Harvard Business Press: Boston, Massachusetts.

Kennedy, T. (2013). Key note presentation at the ANCOR 2013 Conference located at the L'Enfant Hotel in Washington D.C. April 28-30, 2013.

Lipman-Blumen, J. (2004). The allure of toxic leaders: Why we follow destructive bosses and corrupt politicians - how we can survive them. Retrieve from http://www.economist.com/media/ globalexecutive/allure_of_toxic_leaders.pdf

Lund, J. (2014). Train, Retrain and Retain Conference in Spokane Washington. May 15, 2014.

Mank, D. (2008). Alderbrook 2007. Journal of Vocational Rehabilitation, 29(2), 53-62.
McLain, S., \& Walus, M. (2015). Community role in the culture of self-sufficiency. Journal of Vocational Rehabilitation, 42(2015), 235-240. DOI:10.3233/JVR-150744

Momm, W., \& Konig, A. (1989). Community integration for disabled people. A new approach to their vocational training and employment. International Labour Review, 128(4), 497.

O'Brien, J. (2011). Celebrating the genius of Wolf Wolfensberger. Research and Practice for Persons with Severe Disabilities, 36(1-2), 76-79.

Sullivan, J. \& Nord, D. (2015). APSE Conference in Philadelphia.

Sullivan, J., Sutewski, \& Timmons, J.C. (2015). Introduction to Community Life Engagement. Enage, issue 1.

Trajkovski, T., \& Andreevski, V. (2004). Some aspects and relations between altruism, socialization and integration in the process of humanization of the life conditions of disabled persons. Journal of Special Education \& Rehabilitation, (1/2), 109-118.

U.S. Department of Education (2015). Workforce innovation and opportunity act. Retrieved from: http://www2.ed.gov/about/ offices/list/osers/rsa/wioa-reauthorization.html

Wolfensberger, W., \& Nirje, B. (1972). The principle of normalization in human services.

Wolfensberger, W. (1999). A contribution to the history of normalization, with primary emphasis on the establishment of normalization in North America between 1967-1975. A quarter-century of normalization and social role valorization: Evolution and impact, 51-116.

Wolfensberger, W. (2011). Social Role Valorization: A proposed new term for the principle of normalization. Intellectual and developmental disabilities, 49(6), 435-440. 